\title{
Practice Patterns in the Diagnosis and Treatment of Polycythemia Vera in the Post-JAK2 V617F Discovery Era
}

Elizabeth M. Kander, MDª Alison R. Moliterno, MD' ; Alfred Rademaker, PhDª Michael B. Streiff, $\mathrm{MD}^{\mathrm{b}}$; Jerry L. Spivak, MD' ; and Brady L. Stein, MD, MHSa

\begin{abstract}
Polycythemia vera (PV) is an acquired clonal hematopoietic stem cell disorder characterized by an overproduction of red blood cells, white blood cells, and platelets; thrombotic and hemorrhagic complications; and an increased risk of transformation to myelofibrosis and acute leukemia. In 1967, the Polycythemia Vera Study Group proposed the optimal approach to diagnosis and treatment of PV, and in 2002, investigators from Johns Hopkins University School of Medicine surveyed the practice patterns of hematologists as they pertained to PV. Since this survey, the JAK2 V617F mutation was discovered, leading to a new era of discovery in the disease pathogenesis, diagnosis, and classification and treatment of PV. Our objective was to survey hematologists in the diagnosis and treatment of PV in the modern, postJAK2 V617F discovery era. An anonymous 17-question survey was emailed to members of the Myeloproliferative Neoplasm (MPN) Research Foundation database and Aplastic Anemia and MDS International Foundation. A total of 71 surveys were used in the analysis. Diagnostic testing varied according to the respondent's clinical experience and practice type. In addition, there were marked differences in target hematocrit and platelet count among those surveyed. There continue to be variations in diagnosis and treatment of PV despite WHO guidelines and the JAK2 discovery. US-based guidelines for MPNs are needed to create consistency in the management of PV and other MPNs.
\end{abstract}

J Natl Compr Canc Netw 2016;14(10):1238-1245

\section{Background}

Polycythemia vera (PV) is an acquired clonal hematopoietic stem cell disorder characterized by an overproduction of red blood cells (and other mature blood elements), thrombotic and hemorrhagic complications, and transformation to a myelofibrotic and, rarely, an acute leukemic phase. PV carries an incidence rate of 1.0 case per 100,000 persons (prevalence rate of $44-57$ per 100,000 persons) and, in general, is a disease of older age, with the median age at diagnosis of 61 years. ${ }^{1,2}$ The median survival of PV is 18.9 years (range, 10.9-27.8 years based on risk group) and is significantly lower

From the aDepartment of Medicine, Northwestern University Feinberg School of Medicine, Chicago, Illinois; and bJohns Hopkins University School of Medicine, Baltimore, Maryland.

Submitted March 19, 2016; accepted for publication June 2, 2016.

Dr. Moliterno has disclosed that she is on the advisory board for Incyte Corporation. The remaining authors have disclosed that they have no financial interests, arrangements, affiliations, or commercial interests with the manufacturers of any products discussed in this article or their competitors. than age- and sex-matched controls. ${ }^{3,4}$ PV has a chronic course, with thrombosis a major cause of morbidity and mortality. Less common, but feared complications, include transformation to myelofibrosis and acute leukemia. $3,5,6$

In 1967, the Polycythemia Vera Study Group (PVSG) was established to develop the optimal approach to diagnosis and treatment of PV, developing major and minor criteria for diagnosis and investigating management strategies. Of the 3 studied regimens (phlebotomy alone, chemotherapy [chlorambucil] with phlebotomy, and radiotherapy [32 $\mathrm{P}]$ with phlebotomy),

Author Contributions: Main author and data collection: Kander. Involved in survey and study design, manuscript editor: Moliterno. Statistician: Rademaker. Author of original survey instrument in 2002; involved in current survey and study design, editor of current manuscript: Streiff and Spivak. Principal investigator: Stein.

Correspondence: Brady L. Stein, MD, MHS, Division of Hematology/ Oncology, Department of Medicine, Northwestern University Feinberg School of Medicine, 645 Ninth Michigan Avenue, Suite 1020, Chicago, IL 60611. E-mail: brady-stein@northwestern.edu 
improved survival was seen with phlebotomy. In addition, these studies found that the incidence of acute leukemia was increased in patients treated with chlorambucil and ${ }^{32} \mathrm{P}$, and the incidence of myelofibrotic transformation was similar with all 3 treatment modalities. ${ }^{7-9}$

In 2002, investigators from Johns Hopkins University School of Medicine surveyed 1,000 members of the American Society of Hematology (ASH) regarding their practice patterns as they pertained to PV, with the objective to determine the impact of PVSG studies on diagnosis and treatment of erythrocytosis and thrombocytosis. ${ }^{10}$ They found that the most commonly used diagnostic tests included red cell mass studies, erythropoietin levels, and arterial blood gases. The initial therapy used was phlebotomy and most respondents used a target hematocrit of $44 \%$ or less, but a significant minority used targets of $50 \%$ or greater despite PVSG recommendations. Less uniformity was noted regarding the treatment of thrombocytosis; although most clinicians treated a platelet count of greater than $1,000 \times 10^{9} / \mathrm{L}$, a significant number used a lower threshold for treatment, or treated only those with symptomatic thrombocytosis. Hydroxyurea was the most commonly used medication to treat thrombocytosis, especially among academic physicians; otherwise, anagrelide was used by private practice physicians $(44.6 \%$ vs $36.3 \%$ in academic practice; $P=.02$ ) and physicians who had recently completed their training (1-5 years, $51 \%$ vs $>10$ years, $39 \% ; P=.01$ ). Among respondents, $55 \%$ avoided interferon in treatment of thrombocytosis and $15 \%$ avoided aspirin. The study authors concluded that there was considerable variation in the diagnosis and treatment of PV by ASH members depending on region, practice type, specialty, and years of clinical experience.

Since that survey was completed, there has been an immense era of discovery in the pathogenesis, diagnosis, and classification of PV and other myeloproliferative neoplasms (MPNs), mostly due to the discovery of the JAK2 V617F mutation and its role in MPNs. ${ }^{11-15}$ As a result, diagnostic criteria for PV evolved to include this molecular marker and most of the PVSG criteria were abandoned, as was published in the more recently revised WHO diagnostic criteria for PV. ${ }^{16}$ Therapeutic strategies have also expanded, because there is renewed interest in pegylated interferon-alpha because of its promise in achiev- ing molecular and hematologic remission in PV. ${ }^{17}$ Further, ruxolitinib, a JAK1/JAK2 inhibitor, has been approved for $\mathrm{PV}$ in patients with intolerance or resistance to hydroxyurea. ${ }^{18}$ The optimal hematocrit target in PV, which has been debated for 3 decades, has been confirmed to be $45 \%$ or less, according to a recently published randomized study. ${ }^{19,20}$ Finally, although high-dose aspirin was associated with an increased risk of bleeding, a randomized study from the European Collaboration on Low-Dose Aspirin in Polycythemia Vera (ECLAP) investigators suggested that $100 \mathrm{mg}$ of daily aspirin significantly lowered the combined risk of cardiovascular death, nonfatal myocardial infarction, nonfatal stroke, pulmonary embolism, and major venous thrombosis (relative risk, 0.40; 95\% CI, 0.18-0.91). ${ }^{21}$ However, this claim was later challenged in a Cochrane review of 630 patients with $\mathrm{PV}$, which found that low-dose aspirin was associated with a statistically nonsignificant reduction in fatal thrombotic events and all-cause mortality. ${ }^{22}$

The impact of these changes in diagnostic and therapeutic strategies on practice patterns in the modern/post-JAK2 V617F era of PV is unknown, especially because US-based guidelines do not yet exist, but are in development. ${ }^{23}$ Our objective was to again survey hematologists regarding diagnosis and treatment of PV as it applied to the modern, postJAK2 V617F discovery era to evaluate the impact of new diagnostic criteria and treatments for PV.

\section{Methods}

An anonymous Institutional Review Boardapproved a 17-question survey pertaining to the diagnostic and therapeutic strategies for PV, which was disseminated to members of the MPN Research Foundation (MPNRF) database $(\mathrm{N}=847)$ and Aplastic Anemia and MDS International Foundation (AAMDSIF; N=24,061) through an email blast from each foundation inviting members to participate via a hyperlink (Figure 1 ). On the introductory page of the survey, participants were provided information regarding the study's purpose and its voluntary and anonymous nature. By partaking in the survey, participants gave informed consent. One survey was excluded because the surveyor responded that he/she had zero patients with $\mathrm{PV}$ in the practice. All other returned surveys were 
Kander et al

SECTION 1: Demographics

Q1 I consider myself primarily a/an [ ] MD/DO [ ] PhD

Q1B I consider myself primarily a/an [ ] Hematologist

Q2 Where is your primary site of clinical practice? [ ] Private practice setting

[ ] MD/PhD [ ] Industry/Pharmacy

[ ] Oncologist

[ ] Academic practice setting

Q3 How many years of clinical experience have you had since completing training?
[ ] $<1$
[ ] 1-5
[ ] 6-10
[ ] $\geq 11$

Q4 How many PV patients are in your practice?
[ ] 0
[ ] 1-5
[ ] 6-10
[ ] 11-15
[ ] $>16$

SECTION 2: Diagnosis

Q5 What tests or findings do you find useful in diagnosing polycythemia vera? Choose all that apply

[ ] Complete blood count

[ ] JAK2 exon 12 testing

[ ] Presence of splenomegaly

[ ] Arterial oxygen saturation

[ ] Bone marrow aspirate and biopsy

[ ] Cytogenetics

[ ] Endogenous erythroid colony formation

[ ] Red cell mass testing

[ ] Normal hemoglobin with low iron stores

[ ] Vitamin B12 binding protein

Q6 How do you characterize PV to patients?

[ ] Blood disorder or syndrome

[ ] Pre-leukemia/myelodysplastic syndrome

[ ] Blood neoplasm

[ ] Form of cancer

[ ] JAK2 V617F testing

[ ] Erythropoietin level

SECTION 3: Treatment

Q7 What is your target hematocrit for phlebotomy?

[ ] $<42 \%$ for women and $<45 \%$ for men

[ ] $<50 \%$

Q8 What is your platelet target or goal?
[ ] $<400 \times 10^{9} / \mathrm{L}$
[ ] $400-600 \times 10^{9} / \mathrm{L}$
[ ] $<1,000 \times 10^{9} / \mathrm{L}$
[ ] Thrombocytosis is treated only in presence of symptoms

$[$ ] $<45 \%$; I do not distinguish by gender
$[$ ] $<55 \%$

Q9 What prompts you to treat PV with cytoreduction? Choose all that apply

[ ] Erythrocytosis

[ ] Advanced age ( $>60$ years)

[ ] Microvascular complications (transient ischemic attacks, erythromelalgia, visual disturbance, migraine headaches)

[ ] Venous or arterial thrombosis history [ ] Pruritus [ ] Weight loss

[ ] Thrombocytosis

[ ] Leukocytosis [ ] Splenomegaly

Q10 What agents do you use for cytoreduction? Indicate for all as follows: $1=$ preferred agent, 2 =second-line agent

[ ] Anagrelide [ ] Hydroxyurea

[ ] Recombinant interferon-alfa [ ] Busulfan

[ ] Pegylated interferon-alfa

Q11 Do you recommend aspirin for all PV patients (unless contraindicated)?

[ ] Yes [ ] No

Q12 Are there any agents that you avoid due to the side effect profile?
[ ] Anagrelide
[ ] Hydroxyurea
[ ] Phlebotomy
[ ] Pegylated Interferon-alfa
[]$^{32} \mathrm{P}$

[ ] Recombinant Interferon-alfa [ ] Aspirin [ ] Busulfan
Q13 Is there an age range in which you would avoid the use hydroxyurea?

[ ] Recombinant Interferon-alfa [ ] Aspirin [ ] Busulfan
Q13 Is there an age range in which you would avoid the use hydroxyurea?
[ ] Age $\leq 18$ y
[ ] Age $\leq 40$ y
[ ] Age $\leq 60$ y
[ ] No age criteria

Q14A Which of the following agents do you believe can modify the natural history of PV (prevent transformation to myelofibrosis or leukemia)?

[ ] Anagrelide [ ] Hydroxyurea $\quad$ [ ] Phlebotomy

Q14B Which of the following agents do you believe may accelerate/cause the development of myelofibrosis?

[ ] Anagrelide [ ] Hydroxyurea [ ] Phlebotomy
[]

[ ] Pegylated Interferon-alfa [ ] Recombinant interferon-alfa [ ] JAK inhibitors [ ] None of the above

Q14C Which of the following agents do you believe may accelerate/cause the development of leukemia?
[ ] Anagrelide
[ ] Hydroxyurea
[ ] Pegylated interferon-alfa [ ] Recombinant interferon-alfa
[ ] Phlebotomy
Q15 What do you perceive the usefulness of JAK2 inhibitors will be in PV?
[ ] Potential to cure
[ ] Potential to prolong survival
[ ] Improvement of systemic symptoms
[ ] Decrease in phlebotomy needs
[ ] Treatment of thrombocytosis
[ ] Treatment of leukocytosis
[ ] Treatment of splenomegaly

Figure 1. Survey instrument.

used in the data set. After surveys were collected, tables were constructed to compare practice patterns based on independent variables (respondent characteristics). The Fisher exact test was used to compare responses, with a $P$ value of less than 0.05 considered statistically significant. 


\section{Results}

\section{Respondent Characteristics}

A total of 72 people completed the survey and 71 surveys were used for further analysis. Most responses (66 of 71) were from the MPNRF (response rate, $7.8 \%$ ) and the remaining were from the AAMDSIF (response rate, $\approx 0 \%$ ). Education varied in respondents, with most $(67.6 \%)$ an $\mathrm{MD} / \mathrm{DO}, 26.8 \%$ an $\mathrm{MD} / \mathrm{PhD}, 2.8 \%$ a $\mathrm{PhD}$, and $2.8 \%$ industry/pharmacy (Table 1). Most (84.1\%) considered themselves hematologists, and $83.1 \%$ practiced in an academic setting (Table 1); 11.6\% (8 of 69) classified themselves as oncologists; and 4.4\% (3 of 69) classified themselves as hematologists/oncologists. The amount of clinical experience of respondents varied, with most (36 of $69 ; 52.2 \%$ ) having more than 16 years of experience, followed by 12 of $69(17.4 \%)$ having 6 to

\begin{tabular}{|c|c|c|}
\hline & $\begin{array}{l}\text { Number of } \\
\text { Respondents } \\
(\mathrm{N}=71)\end{array}$ & $\%$ \\
\hline \multicolumn{3}{|l|}{ Education } \\
\hline MD/DO & 48 & 67.6 \\
\hline $\mathrm{PhD}$ & 2 & 2.8 \\
\hline MD/PhD & 19 & 26.8 \\
\hline Industry/Pharmacy & 2 & 2.8 \\
\hline \multicolumn{3}{|l|}{ Practice type } \\
\hline Academic & 59 & 83.1 \\
\hline Private & 12 & 16.9 \\
\hline \multicolumn{3}{|l|}{ Specialty ${ }^{a}$} \\
\hline Hematology & 58 & 84.1 \\
\hline Oncology & 8 & 11.6 \\
\hline Hematology/Oncology & 3 & 4.4 \\
\hline \multicolumn{3}{|l|}{ Clinical experience $(y)^{a}$} \\
\hline$<1$ & 4 & 5.8 \\
\hline $1-5$ & 9 & 13.0 \\
\hline $6-10$ & 12 & 17.4 \\
\hline $11-15$ & 8 & 11.6 \\
\hline$>16$ & 36 & 52.2 \\
\hline \multicolumn{3}{|c|}{ Patients seen with polycythemia vera $(\mathrm{N})^{\mathrm{a}}$} \\
\hline $1-5$ & 13 & 18.8 \\
\hline $6-10$ & 13 & 18.8 \\
\hline $11-15$ & 11 & 15.9 \\
\hline$>16$ & 32 & 46.4 \\
\hline
\end{tabular}

a2 respondents did not respond.
10 years of experience; $18.8 \%$ of respondents reported having 5 years or less of clinical experience. Most respondents ( 32 of $69 ; 46.4 \%$ ) reported having 16 or more patients with PV in their practice, whereas 26 of 69 respondents $(37.6 \%)$ reported having 1 to 10 patients with PV.

\section{Diagnosis of PV}

The commonly used tests reported by respondents to diagnose PV were the CBC (91.6\%), JAK2 V617F testing $(90.1 \%)$, and erythropoietin level $(83.1 \%)$ (Figure 2). Bone marrow aspirate/biopsy was more commonly used than red cell mass testing (57\% vs $23 \% ; P<.0001)$. Physicians in an academic setting considered JAK2 V617F testing more useful than those in a private practice $(94.9 \%$ vs $66.7 \%$; $P=.01)$ and there was a trend toward greater use of erythropoietin level in the academic setting (86.4\% vs $66.7 \% ; P=.11$ ) (Table 2 ). There was also a trend toward use of cytogenetics in diagnosing PV among oncologists compared with hematologists (37.5\% vs $13.8 \% ; P=.17$ ) (Table 3 ). Respondents with more patients with $\mathrm{PV}$ in their practice were more likely to report JAK2 V617F testing as useful in diagnosing PV $(P=.01)$, and those with fewer patients with PV in their practice were more likely to report cytogenetics as being useful $(P=.02)$ (Table 4$)$.

When counseling patients, $73.2 \%$ of respondents characterized PV as a blood neoplasm. The next most common characterization was a "blood disorder or syndrome" $(22.5 \%)$; respondents from academic and private practices also characterized PV this way, but in different proportions $(79.7 \%$ and $41.7 \%$ as a blood neoplasm, respectively; $P=.012$ ).

\section{Treatment of PV}

Target hematocrit varied in this cohort. A total of $48 \%$ of respondents used a sex-dependent hematocrit target ( $<42 \%$ for women and $<45 \%$ for men) for phlebotomy, whereas $41.8 \%$ targeted a hematocrit of less than $45 \%$ universally (Figure 3). Target platelet count also varied, with a target of less than $400 \mathrm{x}$ $10^{9} / \mathrm{L}$ being most common (34.3\% of respondents), followed by a target of 400 to $600 \times 10^{9} / \mathrm{L}$ (32.8\% of respondents) (Figure 4). Platelet goals did not vary by practice type or specialty. Although $74.7 \%$ of respondents recommended aspirin for all patients unless contraindicated, respondents in academic practices were more likely to universally recommended 


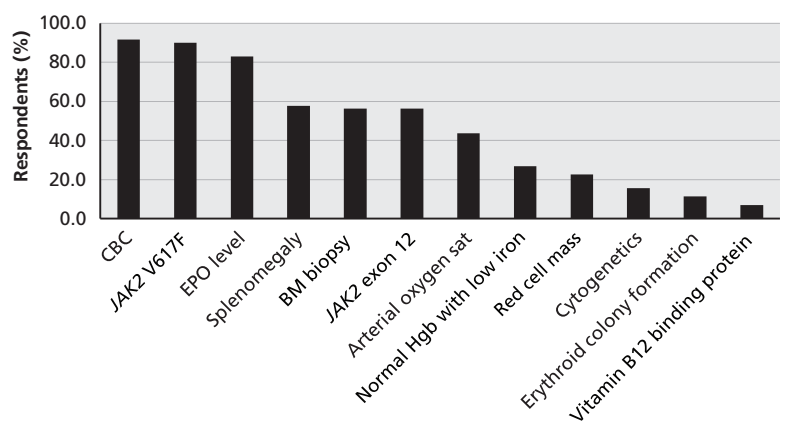

Figure 2. Diagnostic testing reported most useful to diagnose polycythemia vera.

Abbreviations: $\mathrm{BM}$, bone marrow; $\mathrm{CBC}$, complete blood count; EPO, erythropoietin; $\mathrm{Hgb}$, hemoglobin; sat, saturation.

aspirin $(79.7 \%)$ compared with those in private practice $(50 \%)(P=.01)$. A trend was seen for those with fewer years of experience to universally recommend aspirin compared with those with more years of experience $(P=.2)$.

The preferred cytoreductive agent was hydroxyurea $(82 \%)$ (Figure 5), with anagrelide and pegylated interferon (peg-IFN) being the preferred second-line treatments (36.6\% and 35.2\%, respectively). Thrombosis history $(71.8 \%)$, microvascular complications (70.4\%), and age older than 60 years $(56.3 \%)$ were the most common indications for cytoreduction. Almost half of respondents believed thrombocytosis was an indication for cytoreductive therapy (43.7\%); $50.8 \%$ of respondents prescribed hydroxyurea regardless of age, whereas $32.8 \%$ avoided its use in patients younger than 40 years. Respondents with more than 16 years of experience were more likely to prescribe hydroxyurea regardless of patient age compared with those with less experience $(P=.02)$. A total of $28 \%$ of respondents believed that hydroxyurea could accelerate the development of leukemia, and $26.8 \%$ believed that anagrelide could accelerate myelofibrosis. Respondents most commonly avoided ${ }^{32} \mathrm{P}$ (66.2\%), busulfan $(59.2 \%)$, and recombinant interferon-alfa (rIFN) (32.4\%) due to side effects. Respondents believed that peg-IFN (45.1\%), rIFN (33.8\%), and JAK inhibitors (JAKi) (29.6\%) had the potential to modify the natural history of PV. Respondents perceived that JAKi would be most useful in improving symptoms (78.9\%), reducing splenomegaly $(73.2 \%)$, and decreasing phlebotomy needs $(56.3 \%)$; fewer believed in its potential to prolong survival $(33.8 \%)$ or to cure PV $(8.5 \%)$.

\begin{tabular}{|c|c|c|c|}
\hline Diagnostic Test & $\begin{array}{l}\text { Private } \\
(\%)\end{array}$ & $\begin{array}{c}\text { Academic } \\
(\%)\end{array}$ & $P$ Value \\
\hline CBC & 83.3 & 93.2 & .27 \\
\hline $\begin{array}{l}\text { Bone marrow } \\
\text { aspirate/biopsy }\end{array}$ & 41.7 & 59.3 & .34 \\
\hline $\begin{array}{l}J A K 2 \mathrm{~V} 617 \mathrm{~F} \\
\text { testing }\end{array}$ & 66.7 & 94.9 & .01 \\
\hline $\begin{array}{l}\text { JAK2 exon } 12 \\
\text { testing }\end{array}$ & 41.7 & 59.3 & .34 \\
\hline Cytogenetics & 8.3 & 16.9 & .68 \\
\hline $\begin{array}{l}\text { Erythropoietin } \\
\text { level }\end{array}$ & 66.7 & 86.4 & .11 \\
\hline Splenomegaly & 50.0 & 59.3 & .75 \\
\hline $\begin{array}{l}\text { Endogenous } \\
\text { erythroid colony } \\
\text { formation }\end{array}$ & 0 & 13.6 & .34 \\
\hline $\begin{array}{l}\text { Arterial oxygen } \\
\text { saturation }\end{array}$ & 25 & 47.5 & .21 \\
\hline $\begin{array}{l}\text { Red cell mass } \\
\text { testing }\end{array}$ & 8.3 & 25.4 & .27 \\
\hline $\begin{array}{l}\text { Normal } \\
\text { hemoglobin with } \\
\text { low iron stores }\end{array}$ & 25 & 27.1 & .99 \\
\hline $\begin{array}{l}\text { Vitamin B12 } \\
\text { binding protein }\end{array}$ & 8.3 & 6.8 & .99 \\
\hline
\end{tabular}

\section{Discussion}

This article presents results from a survey of practice patterns in the diagnosis and treatment of $\mathrm{PV}$ in the modern/post-JAK2 V617F era as a follow-up to the 2002 survey conducted by Johns Hopkins University. ${ }^{10}$ Our survey focused on the diagnosis of PV and its treatment strategies, including concerns regarding long-term adverse effects and the potential for future therapies. Most of the respondents were experienced academic hematologists with medical degrees.

Regarding diagnostic strategies, it appears that hematologists/oncologists have adopted WHO criteria, because the respondents considered CBC, JAK2 V617F testing, and erythropoietin levels to be the most useful diagnostic tools. However, practice type did influence the preferred diagnostic test. Academic physicians were more likely than those in private practice to use JAK2 V617F testing, and there was a trend toward greater use of erythropoietin levels. Clinical experience also influenced diagnostic testing: physicians with more patients with PV in their practice were more likely than those with fewer patients to use JAK2 testing, whereas clinicians with 
Practice Patterns of Polycythemia Vera

\section{Table 3. Diagnostic Testing by Specialty}

\begin{tabular}{|c|c|c|c|c|}
\hline Diagnostic Test & Hematology (\%) & Oncology (\%) & Hematology/Oncology (\%) & $P$ Value \\
\hline CBC & 93.1 & 87.5 & 100 & .59 \\
\hline Bone marrow aspirate/biopsy & 58.6 & 50.0 & 66.7 & .88 \\
\hline JAK2 V617F testing & 91.4 & 87.5 & 100 & .66 \\
\hline JAK2 exon 12 testing & 60.3 & 50.0 & 33.3 & .59 \\
\hline Cytogenetics & 13.8 & 37.5 & 0 & .17 \\
\hline Erythropoietin level & 82.8 & 100 & 66.7 & .25 \\
\hline Splenomegaly & 58.6 & 50.0 & 66.7 & .88 \\
\hline Endogenous erythroid colony formation & 13.8 & 0 & 0 & .71 \\
\hline Arterial oxygen saturation & 44.8 & 50.0 & 33.3 & .99 \\
\hline Red cell mass testing & 27.6 & 0 & 0 & .24 \\
\hline Normal hemoglobin with low iron stores & 29.3 & 12.5 & 33.3 & .63 \\
\hline Vitamin B12 binding protein & 8.6 & 0 & 0 & .99 \\
\hline
\end{tabular}

fewer patients with PV were more likely to report cytogenetics as a useful diagnostic test. There was also a trend toward using cytogenetics among oncologists compared with hematologists.

There was considerable variation in PV treatment among respondents. Interestingly, there was an almost even divide in goal target hematocrit between a sex-dependent hematocrit goal $(47.8 \%$ of respondents) and a hematocrit goal of less than $45 \%$ regardless of sex (41.8\% of respondents), despite recent recommendations that phlebotomy should target the latter. In addition, similar to the 2002 survey study, there was a significant minority $(10.5 \%)$ that used a target hematocrit of $50 \%$ or greater. Target platelet goals varied significantly in this cohort, with almost one-third of respondents treating for target less than $400 \times 10^{9} / \mathrm{L}, 400$ to $600 \times 10^{9} / \mathrm{L}$, and only if symptomatic, respectively, which is not surprising given that there are no guidelines on this topic and platelet count has shown no correlation with thrombotic events. ${ }^{24}$ Given these inconsistencies, practitioners would benefit from US-based guidelines for the management of PV and other MPNs.

Respondents did not universally recommend aspirin to all patients with PV. Physicians in private practice were significantly less likely to prescribe

\section{Table 4. Diagnostic Testing by Number of Patients With Polycythemia Vera in Practice}

\begin{tabular}{|c|c|c|c|c|c|}
\hline Diagnostic Test & 1-5 Patients (\%) & 6-10 Patients (\%) & $11-15$ Patients $(\%)$ & $\geq 16$ Patients $(\%)$ & $P$ Value \\
\hline $\mathrm{CBC}$ & 92.3 & 84.6 & 100.0 & 96.9 & .33 \\
\hline Bone marrow aspirate/biopsy & 53.8 & 38.5 & 72.7 & 62.5 & .33 \\
\hline JAK2 V617F testing & 84.6 & 76.9 & 100.0 & 100.0 & .01 \\
\hline JAK2 exon 12 testing & 46.2 & 53.8 & 54.5 & 65.6 & .63 \\
\hline Cytogenetics & 30.8 & 30.8 & 18.2 & 3.1 & .02 \\
\hline Erythropoietin level & 76.9 & 92.3 & 81.8 & 87.5 & .67 \\
\hline Splenomegaly & 53.8 & 53.8 & 72.7 & 59.4 & .77 \\
\hline $\begin{array}{l}\text { Endogenous erythroid colony } \\
\text { formation }\end{array}$ & 7.7 & 7.7 & 0 & 18.8 & .49 \\
\hline Arterial oxygen saturation & 61.5 & 53.8 & 36.4 & 37.5 & .42 \\
\hline Red cell mass testing & 23.1 & 23.1 & 36.4 & 18.8 & .67 \\
\hline $\begin{array}{l}\text { Normal hemoglobin with low iron } \\
\text { stores }\end{array}$ & 23.1 & 30.8 & 27.3 & 28.1 & 1.00 \\
\hline Vitamin B12 binding protein & 7.7 & 0 & 0 & 12.5 & .63 \\
\hline
\end{tabular}




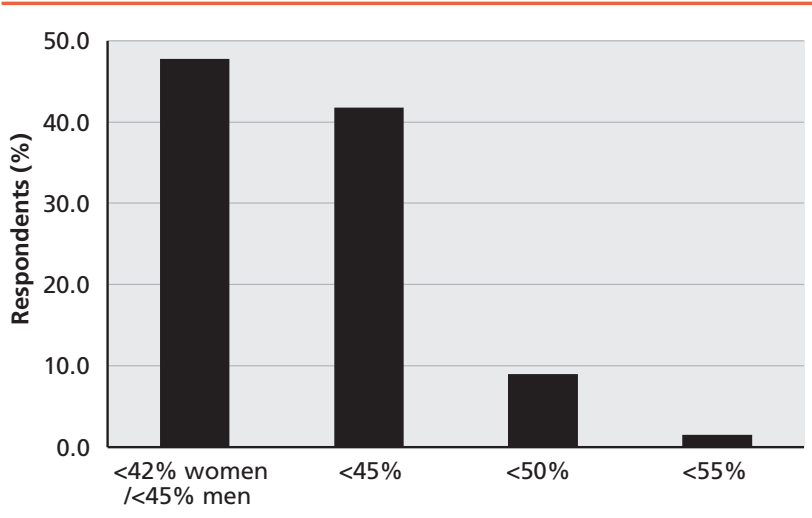

Figure 3. Target hematocrit in polycythemia vera.

aspirin compared with physicians in academic practice. In addition, a trend was seen for physicians who recently completed training to universally recommend aspirin more often than the most experienced practitioners. This difference may reflect awareness of previous data from the PVSG that associated the 325 -mg dose of aspirin with higher rates of hemorrhage. ${ }^{25}$

Most respondents agreed on cytoreductive strategies and its indications, with hydroxyurea being the preferred agent in $82 \%$ of respondents, and thrombosis history, microvascular complications, and age older than 60 years being the most common indications. The evidence base for use of hydroxyurea in PV is actually scarce, ${ }^{26}$ with efficacy typically extrapolated from results in randomized studies of patients with essential thrombocytopenia. ${ }^{27-29}$ Almost one-third of respondents avoided hydroxyurea in patients younger than 40 years, likely due to fears that it could accelerate transformation to leukemia, as $28 \%$ of respondents believed. The association between hydroxyurea and secondary leukemia is controversial, and difficult to prove with certainty given the limitations of studies examining this question. ${ }^{30}$ The more experienced respondents were more likely to prescribe hydroxyurea regardless of age compared with less experienced respondents, and $66 \%$ of respondents avoided ${ }^{32} \mathrm{P}$ due to potential side effects. Interestingly, peg-IFN was thought by many (45\%) to modify the natural history of PV, but it was not the preferred first- or second-line cytoreductive agent, likely due to its many side effects. Lastly, most respondents believed that JAKi were useful for improving symptoms and reducing splenomegaly, and fewer believed it had the potential to cure PV. This

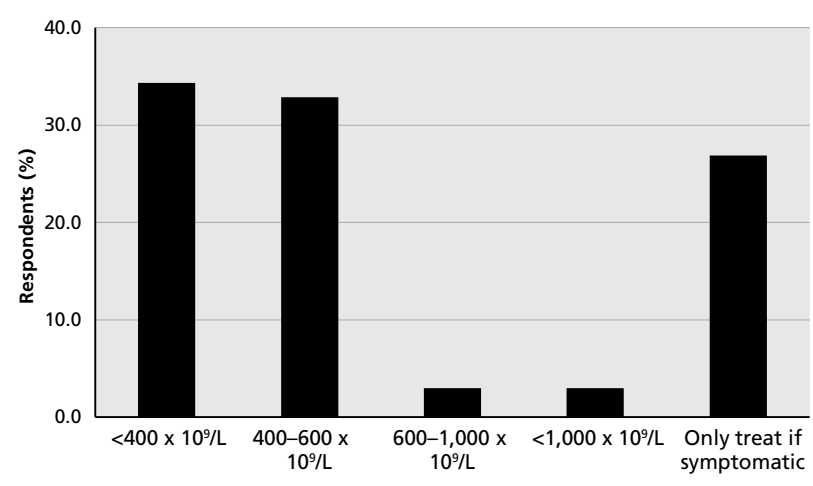

Figure 4. Target platelet count in polycythemia vera.

perception is in keeping with clinical data regarding improvement in symptom burden.

In the more than 10 years since the prior survey, differences and similarities can be seen in the respondents' diagnostic and therapeutic strategies for treating PV. Diagnostics now heavily rely on newly discovered molecular testing, and the use of red cell mass and arterial blood gas has decreased considerably. Cytogenetics have recently been reported to have a significant influence on prognosis, and the impact of additional somatic mutations identified by next-generation sequencing is under evaluation. Target platelet count has become more variable; in 2002, most respondents initiated treatment for patients with platelet counts greater than $1,000 \mathrm{x}$ $10^{9} / \mathrm{L}$, which is now the minority opinion. Commonly a trigger for treatment, the platelet count itself has not been shown to correlate with thrombosis. ${ }^{24,31}$ In regard to the hematocrit threshold for treatment, there is a persistent minority of respondents who continue to target a hematocrit of $50 \%$ or greater. Hydroxyurea continues to be the preferred cytoreductive agent both then and today, and respondents continue to avoid busulfan and ${ }^{32} \mathrm{P}$.

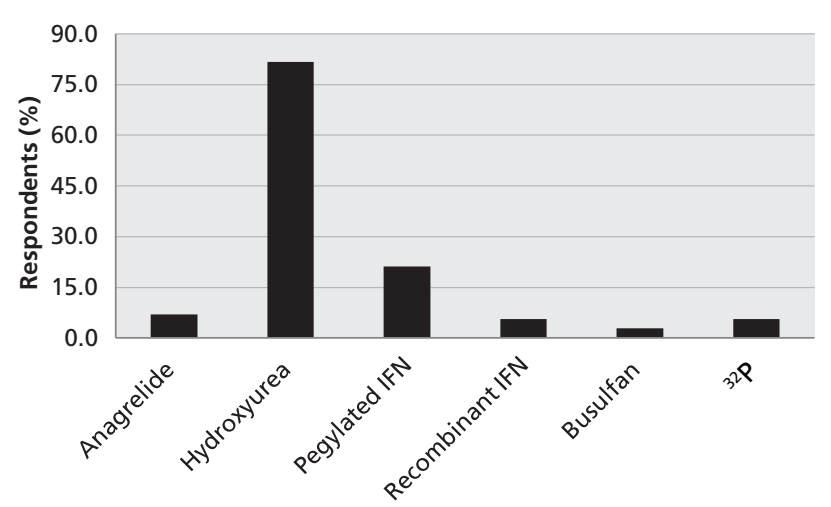

Figure 5. Preferred cytoreductive therapy in polycythemia vera. Abbreviation: IFN, interferon. 
Practice Patterns of Polycythemia Vera

There are limitations of this study. Respondents were primarily academic hematologists, which may skew responses. However, this is the physician subgroup that has the most exposure to and experience with treating patients with PV. Furthermore, despite the large proportion of academic hematologists among respondents, there was still considerable heterogeneity with regard to some aspects of PV management. Our response rate was low, with less than $8 \%$ of MPNRF members responding and even fewer members of the AAMDSIF. Despite a lower-than-hoped-for response rate, this survey serves a role as a "pre-guideline" view of PV practice - thankfully, the first US-based guidelines for MPNs are in development. ${ }^{23}$

\section{Conclusions}

This article presents results of a survey of practice patterns in the diagnosis and treatment of PV in the modern/post-JAK2 V617F era as a follow-up to the 2002 survey conducted by Johns Hopkins University. ${ }^{10}$ There continue to be considerable variations in the diagnosis and treatment of PV. Practitioners would benefit from US-based guidelines for MPNs, which are currently in development.

Editor's Note: The NCCN Guidelines for MPNs were recently released and are available at NCCN.org. They will also be published in the December 2016 issue of JNCCN.

\section{References}

1. Rollison DE, Howlander N, Smith MT, et al. Epidemiology of myelodysplastic syndromes and chronic myeloproliferative disorders in the United States, 2001-2004, using data from the NAACCR and SEER programs. Blood 2008;112:45-52.

2. Mehta J, Wang H, Iqbal SU, Mesa R. Epidemiology of myeloproliferative neoplasms in the United States. Leuk Lymphoma 2014;55:595-600.

3. Passamonti F, Rumi E, Pungolino E, et al. Life expectancy and prognostic factors for survival in patients with polycythemia vera and essential thrombocythemia. Am J Med 2004;117:755-761.

4. Tefferi A, Rumi E, Finazzi G, et al. Survival and prognosis among 1545 patients with contemporary polycythemia vera: an international study. Leukemia 2013;27:1874-1881.

5. Finazzi G, Caruso V, Marchioli R, et al; ECLAP Investigators. Acute leukemia in polycythemia vera: an analysis of 1638 patients enrolled in a prospective observational study. Blood 2005;105:2664-2670.

6. Alvarez-Larrán A, Bellosillo B, Martínez-Avilés L, et al. Postpolycythaemic myelofibrosis: frequency and risk factors for this complication in 116 patients. Br J Haematol 2009;146:504-509.

7. Berk PD, Wasserman LR, Fruchtman SM, Goldberg JD. Treatment of polycythemia vera: a summary of clinical trials conducted by the Polycythemia Vera Study Group. In: Wasserman LR, Berk PD, Berlin NI, eds. Polycythemia Vera and the Myeloproliferative Disorders. Philadelphia, PA: WB Saunders; 1995:166-194.

8. Berk PD, Goldberg JD, Silverstein MN, et al. Increased incidence of acute leukemia in polycythemia vera associated with chlorambucil therapy. $\mathrm{N}$ Engl J Med 1981;304:441-447.
9. Berk PD, Goldberg JD, Donovan PB, et al. Therapeutic recommendations in polycythemia vera based on Polycythemia Vera Study Group protocols. Semin Hematol 1986;23:132-143.

10. Streiff MB, Smith B, Spivak JL. The diagnosis and management of polycythemia vera in the era since the Polycythemia Vera Study Group: a survey of American Society of Hematology members' practice patterns. Blood 2002;99:1144-1149.

11. Baxter EJ, Scott LM, Campbell PJ, et al. Acquired mutation of the tyrosine kinase JAK2 in human myeloproliferative disorders. Lancet 2005;365:1054-1061.

12. James C, Ugo V, Le Couedic JP, et al. A unique clonal JAK2 mutation leading to constitutive signalling causes polycythaemia vera. Nature 2005;434:1144-1148.

13. Kralovics R, Passamonti F, Buser AS, et al. A gain-of-function mutation of JAK2 in myeloproliferative disorders. N Engl J Med 2005;352:1779-1790.

14. Levine RL, Wadleigh $M$, Cools J, et al. Activating mutation in the tyrosine kinase JAK2 in polycythemia vera, essential thrombocythemia, and myeloid metaplasia with myelofibrosis. Cancer Cell 2005;7:387-397.

15. Stein BL, Oh S, Berenzon D, et al. Polycythemia vera: an appraisal of the biology and management 10 years after the discovery of JAK2 V617F. J Clin Oncol 2015;33:3953-3960.

16. Vardiman JW, Thiele J, Arber DA, et al. The 2008 revision of the World Health Organization (WHO) classification of myeloid neoplasms and acute leukemia: rationale and important changes. Blood 2009;114:937-951.

17. Kiladjian JJ, Cassinat B, Chevret $S$, et al. Pegylated interferon-alfa-2a induces complete hematologic and molecular responses with low toxicity in polycythemia vera. Blood 2008;112:3065-3072.

18. Verstovsek S, Passamonti F, Rambaldi A, et al. A phase 2 study of ruxolitinib, an oral JAK1 and JAK2 Inhibitor, in patients with advanced polycythemia vera who are refractory or intolerant to hydroxyurea. Cancer 2014;120:513-520.

19. Marchioli R, Finazzi G, Specchia G, et al. Cardiovascular events and intensity of treatment in polycythemia vera. N Engl J Med 2013;368:22-33.

20. Spivak JL. Polycythemia vera, the hematocrit, and blood-volume physiology. N Engl J Med 2013;368:76-78.

21. Landolfi R, Marchioli R, Kutti J, et al. Efficacy and safety of low-dose aspirin in polycythemia vera. N Engl J Med 2004;350:114-124.

22. Squizzato A, Romualdi E, Passamonti F, Middeldorp S. Antiplatelet drugs for polycythaemia vera and essential thrombocythaemia. Cochrane Database Syst Rev 2013:CD006503.

23. Stein BL, Gotlib J, Arcasoy M, et al. Historical views, conventional approaches, and evolving management strategies for myeloproliferative neoplasms. J Natl Compr Canc Netw 2015;13:424-434.

24. Di Nisio M, Barbui T, Di Gennaro L, et al; European Collaboration on Low-dose Aspirin in Polycythemia Vera (ECLAP) Investigators. The haematocrit and platelet target in polycythemia vera. Br J Haematol 2007;136:249-259.

25. Tartaglia AP, Goldberg JD, Berk PD, Wasserman LR. Adverse effects of antiaggregating platelet therapy in the treatment of polycythemia vera. Semin Hematol 1986;23:172-176.

26. Najean Y, Rain JD. Treatment of polycythemia vera: the use of hydroxyurea and pipobroman in 292 patients under the age of 65 years. Blood 1997;90:3370-3377.

27. Cortelazzo S, Finazzi G, Ruggeri M, et al. Hydroxyurea for patients with essential thrombocythemia and a high risk of thrombosis. N Engl J Med 1995;332:1132-1136.

28. Harrison CN, Campbell PJ, Buck G, et al; United Kingdom Medical Research Council Primary Thrombocythemia 1 Study. Hydroxyurea compared with anagrelide in high-risk essential thrombocythemia. N Engl J Med 2005;353:33-45.

29. Gisslinger H, Gotic M, Holowiecki J, et al; ANAHYDRET Study Group. Anagrelide compared with hydroxyurea in WHO-classified essential thrombocythemia: the ANAHYDRET Study, a randomized controlled trial. Blood 2013;121:1720-1728.

30. Mascarenhas J, Mesa R, Prchal J, Hoffman R. Optimal therapy for polycythemia vera and essential thrombocythemia can only be determined by the completion of randomized clinical trials. Haematologica 2014;99:945-949.

31. Campbell PJ, MacLean C, Beer PA, et al. Correlation of blood counts with vascular complications in essential thrombocythemia: analysis of the prospective PT1 cohort. Blood 2012;120:1409-1401. 